\title{
The effects of technical knowledge related to garment production process on fashion designers' designs
}

Fatma Gursoy*,

Nurgul Kilinc,

Suggested Citation:

Global Journal on Humanites \& Social Sciences.

Abstract 
1. Introduction 
2. Methodology of Research

"smile 


\section{Findings}

"summer 2017 collection"

3.1. Findings related to the First Sub Problem

CREATIVITY 
CREATIVITY

3.2. Findings related to the Second sub Problem 
3.3. Comparison of the Illustrations of Designers with and without Technical Knowledge in Terms of Creativity and the Commercial Value

Designers without Technical
Knowledge
$\begin{array}{ccc}1 \text { st } \quad 2 \text { nd } \quad \text { Avarage } \\ \text { illustration illustration }\end{array}$ Score

\section{Designers with Technical Knowledge}

$3 \mathrm{rd}$

illustration 
4. Discussion 
Erciyes University Institue

Elementary exploring the Learning Method II. Creativity and Its Impact on the Level Mathematics Students

Economic Approach, volume:

When Clothes Become Fashion: Design and Innovation System

products,

Fashion trend forecasting and analysis of the level of consumer expectation fashion

Encyclopedia of Creativity

To Develop an Assessment Tool for the Evaluation of Designs in Fashion Design Education 